Bryn Mawr College

Scholarship, Research, and Creative Work at Bryn Mawr College

Graduate School of Social Work and Social

Graduate School of Social Work and Social

Research Faculty Research and Scholarship

Research

2010

\title{
Toward Evidence-Informed Policy and Practice in Child Welfare
}

Julia H. Littell

Bryn Mawr College, jlittell@brynmawr.edu

Aron Shlonsky

Let us know how access to this document benefits you.

Follow this and additional works at: http://repository.brynmawr.edu/gsswsr_pubs

Part of the Social Work Commons

\section{Custom Citation}

Littell, Julia H., and Aron Shlonsky. "Toward Evidence-Informed Policy and Practice in Child Welfare." Research on Social Work Practice 20, no. 6 (2010): 723-725, doi: 10.1177/1049731509347886.

This paper is posted at Scholarship, Research, and Creative Work at Bryn Mawr College. http://repository.brynmawr.edu/gsswsr_pubs/39

For more information, please contact repository@brynmawr.edu. 
Running Head: EVIDENCE-INFORMED CHILD WELFARE

Toward Evidence-Informed Policy and Practice in Child Welfare

\author{
Julia H. Littell \\ Bryn Mawr College \\ Aron Shlonsky \\ University of Toronto
}

Keywords: child welfare, evidence-based practice, evidence-informed practice, research synthesis

Authors' Note: This essay was originally part of a working paper, titled "Better Evidence for a Better World," which was edited by Mark W. Lipsey and Eamonn Noonan for The Campbell Collaboration, and published in 2009 by the International Initiative for Impact Evaluation (3ie). The working paper can be found at http://www.3ieimpact.org/page.php?pg=papers. This essay was invited and accepted by the Editor. Address correspondence concerning this article to: Julia H. Littell, Graduate School of Social Work and Social Research, Bryn Mawr College, 300 Airdale Road, Bryn Mawr, PA, 19010; email: jlittell@brynmawr.edu. 


\begin{abstract}
Drawing on the authors' experience in the international Campbell Collaboration, this essay presents a principled and pragmatic approach to evidence-informed decisions about child welfare. This approach takes into account the growing body of empirical evidence on the reliability and validity of various methods of research synthesis. It also considers wide variations in the cultural, economic, and political contexts in which policy and practice decisions are made-and the contexts in which children live and die. This essay illustrates the use of Campbell and Cochrane systematic reviews to inform child welfare decisions in the diverse contexts that exist around the globe.
\end{abstract}

[100 words] 
Toward Evidence-Informed Policy and Practice in Child Welfare

All societies care about the welfare of children, though childcare practices and definitions of child maltreatment vary across cultures. Child welfare policies are shaped by local values, beliefs, and resources; these include convictions about the nature and scope of public (or community) responsibilities for dependent children, beliefs about what is good and bad for children, and competing claims for public and charitable funds. In some countries, children receive psychosocial services, material assistance, and/or alternative living arrangements in attempts to protect them from harm and promote healthy development. In wealthy nations, child welfare and child protection services may be seen as an integral component of social care (e.g., in Norway) or a set of residual programs for children and families whose needs are not met elsewhere (e.g., in the US). In some low- and middle-income countries, child welfare services are virtually nonexistent, as are organized efforts to identify child maltreatment.

Important advances in research have increased our ability to identify vulnerable children, assess their needs, track their whereabouts, and measure the impacts of social and behavioral interventions on children's safety and well-being (Lindsey \& Shlonsky, 2008). Thus, we must find ways to use research evidence judiciously and in concert with other concerns if we are to succeed in protecting and enhancing the welfare of children.

We know that child welfare programs can have unintended, negative consequences and hidden effects, yet we have the means to detect such effects. For example, the earliest observational studies of "intensive family preservation programs" (IFPS) in the USA showed that abused and neglected children tended to remain with their families after brief, intensive, inhome services. It was not until these programs were subjected to randomized controlled trials 
that it became clear that most of these children would have remained at home even in the absence of IFPS. Further, it was discovered that IFPS could actually increase the detection of subsequent child maltreatment and, thus, increase the likelihood that children would be removed from their families (Littell \& Schuerman, 1995). While this result may (or may not) be desirable for children, it was clearly not the intended outcome.

Increasingly decision makers have demanded evidence about the effects of child welfare interventions. For example, when the US Congress approved \$1 billion in funding for IFPS in 1993, it directed the US Department of Health and Human Services to conduct a multi-site, randomized experiment to test the effects of these programs on subsequent child maltreatment and out-of-home placements (Westat, 2002).

On the other hand, many innovations in child welfare have not been closely linked to evidence. The child welfare field seems to embrace one reform movement after another, even if the new reform is just an old wine in a new bottle. Child welfare program administrators have been drawn to branded interventions, which have sometimes been adopted on the basis of scant evidence.

Widespread implementation of ineffective programs can have serious financial, human, and opportunity costs. The costs of being wrong can be every bit as devastating in child welfare as in health care. In child protection services, for instance, children can be severely harmed by their parents or wrongfully taken from their families. Ineffective treatment of behavioral problems in childhood can lead to extraordinary painful and costly problems in adulthood. A little evidence goes a long way

Government and professional organizations have developed criteria to determine which interventions are effective for problems related to child maltreatment. Many organizations 
produce lists of "effective" programs and practices. These lists are important because they affect funding and policy decisions that will determine the future of child welfare services.

Several prominent groups use consensus-based standards of evidence to identify "evidence-based" programs that are implemented in child welfare settings. Examples include the California Evidence-based Clearinghouse (CEBC) for child welfare (http://www.cachildwelfareclearinghouse.org/), Blueprints for Violence Prevention (Mihalic, Fagan, Irwin, Ballard \& Elliott, 2004), the U.S. National Registry of Evidence-based Programs and Practices (SAMHSA, 2009), Coalition for Evidence Based Policy (http://www.evidencebasedprograms.org/), and the American Psychological Association (APA) Clinical Psychology Division (Chambless, Baker, Baucom, Beutler, Calhoun, Crits-Christoph, et al., 1998). Most of these groups require two controlled trials showing some evidence of positive effects for a program to reach the "top tier" or "model program" status. These criteria allow programs with little evidence to achieve the highest rating. A comprehensive review of all of the relevant evidence (including grey literature) is not required, careful assessments of study methodology and implementation issues are not required, conflicts of interest are not always considered, nor is it necessary to consider whether results may be generalized to other populations and other settings. Such disregard for the basic principles of research synthesis can result in endorsements of programs that have little effect, have unintended consequences, or may even prove harmful (principles and methods of research synthesis are described by Cooper, Hedges \& Valentine, 2009; Higgins \& Green, 2008; and Littell, Corcoran, \& Pilai, 2008). Indeed much of what passes for empirical knowledge about the effects of child welfare programs is not based on sound principles of research synthesis. Instead, most sources of 
information on "programs that work" are derived from unsystematic, partial, and potentially biased summaries of research evidence.

For instance, to our knowledge there is no systematic review of research on the effects of IFPS in cases of child maltreatment. Some reviewers of this literature have expresses preferences for certain studies based on the outcomes of those studies with little attention to their methodological rigor (Littell, 1995). Thus, some reviews merely reflect proponents' opinions. Campbell and Cochrane reviews related to child welfare

Systematic reviews have been generated by authors working with the Campbell Collaboration and the Cochrane Collaboration to address key questions in child welfare policy and practice. Here we describe three such reviews (other examples are: Donkoh, Underhill \& Montgomery, 2006; Macdonald, Ramchandani \& Higgins, 2006; Macdonald \& Turner, 2008; Turner, Macdonald \& Dennis, 2007; Zwi, Woolfenden, Wheeler, O’Brien, Tait \& Williams, 2007).

In response to concerns about the perceived failings of IFPS in child welfare, some observers suggested that child welfare programs should adopt Multisystemic Therapy (MST), a "model program" that was originally developed in juvenile justice settings. Indeed, MST has been widely replicated in diverse settings on the basis of nonsystematic reviews that claim that MST is effective across problems and populations (Littell, 2008). A joint Campbell and Cochrane review found that MST was not consistently better or worse than any of the alternatives to which it had been compared (Littell, Popa \& Forsythe, 2005).

An award-winning Campbell/Cochrane review compared outcomes of kinship foster care with those of traditional, non-relative foster care (Winokur, Holtan, \& Valentine, 2009). Results suggest that children placed with relatives demonstrated better developmental and mental health 
outcomes, and had more stable living arrangements. Further, there were no differences between kinship care and regular foster care in terms of rates of reunification of children with birth parents. Children placed in non-kin foster homes were more likely to be adopted and more likely to use mental health services. Although methodological limitations of the original studies necessitate caution in interpreting results, this review added much-needed information to a longstanding debate about the relative merits of kinship care and foster care.

Less attention has been paid to diagnostic and prognostic questions in the fields of social care than in medicine, yet the implications of incorrect assessments are every bit as far-reaching. In child welfare, families investigated for child maltreatment are assessed for the likelihood that they will injure their children in the future. An incorrect prognosis can lead to the wrongful removal of children from their parents or, likewise, leave children in harm's way. Campbell's first systematic review of prognostic tools will ascertain the psychometric properties of several widely used risk assessment instruments in an effort to maximize the use of reliable and valid predictors of further maltreatment (Shlonsky, Saini, \& Wu, 2007).

Putting it all together: Evidence-informed decisions

Although rigorous evidence about the impacts of child welfare programs and policies is needed to inform policy and practice, this evidence cannot tell us what to do. Even the best evidence must be combined with other considerations to formulate wise decisions. For example, if intensive, in-home services do not prevent (and might increase) the removal of maltreated children from their homes, what should policy makers and practitioners do? The answer depends, in part, on their goals: If protecting children is paramount, then intensive services offer some advantages; if preserving families is paramount, other approaches should be tried. 
If MST is no more or less effective than its alternatives, then our choices can be based on other considerations. Following the publication of the Campbell/Cochrane MST review, MST was adopted in some jurisdictions because decision makers liked the structure and documentation that it provides. Elsewhere MST was abandoned because it was seen as too costly or inconsistent with local cultural norms. All of these decisions are legitimate, in light of the current best evidence of the program's impact.

The widespread adoption of "model" programs can squelch innovation and adaptations necessary to: meet individual needs, respond to local conditions, and respect cultural traditions. As in medicine, evidence-informed policy and practice in child welfare should increase our options, not restrict them (Dickersin, Straus \& Bero, 2007).

\section{Conclusions}

Decision makers need comprehensive, reliable, and unbiased syntheses of credible evidence to make well-informed choices. They need to know about the accuracy of the decisionmaking tools and the impacts of child welfare services for various problems, populations, and settings. Systematic reviews can provide such evidence, thus they are essential for decisionmaking in child welfare. Decision makers must, however, use this evidence judiciously and in concert with other concerns. 


\section{References}

Chambless, D. L., Baker M. J., Baucom D. H., Beutler, L. E., Calhoun, K. S., Crits-Christoph, P., et al. (1998). Update on empirically validated therapies, II. The Clinical Psychologist, 51, 3-16.

Cooper, H., Hedges, L., \& Valentine, J. (Eds.). (2009). Handbook of research synthesis and meta-analysis, 2nd edition. New York: Russell Sage Foundation.

Dickersin, K., Straus, S. \& Bero, L. (2007). Evidence based medicine: increasing, not dictating, choice. British Medical Journal, 334(1), s10.

Donkoh, C., Underhill, K., \& Montgomery, P. (2006). Independent living programmes for improving outcomes for young people leaving the care system. Cochrane Database of Systematic Reviews, 3, Art. No.: CD005558.

Higgins, J. P. T., \& Green, S. (Eds.). (2008). Cochrane Handbook for Systematic Reviews of Interventions (5.0.1 ed.). Chichester, UK: John Wiley \& Sons, Ltd.

Lindsey, D., \& Shlonsky, A. (2008). Child Welfare Research: An Introduction. In D. Lindsey and A. Shlonsky (Eds.). Child welfare research: Advances for practice and policy (1-12). New York: Oxford University Press.

Littell, J. H. (1995). Evidence or assertions? The outcomes of family preservation services. Social Service Review, 69, 338-351.

Littell, J. H. (2008). Evidence-based or biased? The quality of published reviews of evidencebased practices. Children and Youth Services Review, 30, 1299-1317.

Littell, J. H., Corcoran, J., \& Pilai, V. (2008). Systematic Reviews and Meta-analysis. New York: Oxford University Press.

Littell, J. H., Popa, M., \& Forsythe, B. (2005). Multisystemic therapy for social, emotional, and 
behavioral problems in youth aged 10-17. Cochrane Database of Systematic Reviews, 4 , Art. No.: CD004797, DOI: 10.4073/csr.2005.1.

Littell, J. H., \& Schuerman, J. R. (1995). A synthesis of research on family preservation and family reunification programs. Rockville, MD: Westat. Available at: http://aspe.hhs.gov/hsp/cyp/fplitrev.htm.

Macdonald, G., Ramchandani, P., \& Higgins J. (2006). Cognitive-behavioural interventions for children who have been sexually abused. Cochrane Database of Systematic Reviews, 4. Art. No.: CD001930.

Macdonald, G. \& Turner, W. (2008). Treatment Foster Care for improving outcomes in children and young people. Cochrane Database of Systematic Reviews, 1, Art. No.:

\section{CD005649.}

Mihalic, S., Fagan, A., Irwin, K., Ballard, D., \& Elliott, D. (2004). Blueprints for violence Prevention. Washington, DC: U.S. Department of Justice Office of Juvenile Justice and Delinquency Prevention.

Shlonsky, A., Saini, M., \& Wu, M.-J. (2007). The recurrence of child maltreatment: Predictive validity of risk assessment instruments. Protocol. The Campbell Library. Avail at: http://www.campbellcollaboration.org/library.php

Turner W., Macdonald, G., \& Dennis J. (2007). Behavioural and cognitive behavioural training interventions for assisting foster carers in the management of difficult behaviour. Cochrane Database of Systematic Reviews 2007, 1, Art. No.: CD003760.

U.S. Substance Abuse and Mental Health Services Administration (SAMHSA). (2009). National Registry of Evidence-based Programs and Practices. Available at: http://www.nrepp.samhsa.gov/ 
Westat. (2002). Evaluation of Family Preservation and Reunification Programs: Final report. Rockville, MD: Author. Avail at: http://aspe.hhs.gov/hsp/evalfampres94/Final/index.htm.

Winokur, M., Holtan, A., \& Valentine, D. (2009). Kinship care for the safety, permanency, and well-being of children removed from the home for maltreatment. Cochrane Database of Systematic Reviews, 1, Art. No.: CD006546, DOI: 10.4073/csr.2009.1.

Zwi, K., Woolfenden, S., Wheeler, D., O’Brien, T., Tait, P., \& Williams, K. (2007). Schoolbased education programmes for the prevention of child sexual abuse. Cochrane Database of Systematic Reviews, 3, Art. No.: CD004380. 